\title{
A Research of Active Power Filter Based on Feed-Forward Control
}

\author{
Xin Tang \\ Changsha University of Science and Technology \\ CSUST \\ Changsha,China \\ e-mail: csutangxin1@163.com
}

\author{
Qi Wang \\ Changsha University of Science and Technology \\ CSUST \\ Changsha,China \\ e-mail:wangqi924@qq.com
}

\begin{abstract}
This paper proposed a feed-forward control strategy for active power filter. The feed-forward controller and the current controller are designed based on the state-space averaging model and the voltage controller is designed based on the power model. Since the grid voltage may generate big impulsive current during system startup, the feed-forward controller effectively reduces the effect of perturbing grid voltage and DC voltage on controlled current to improve the dynamic performance of system. The reference current for grid current control is directly obtained from the DC voltage control loop, which simplifies the control algorithm. The detection of load current and inverter output current are cancelled, and it is also unneeded for the PLL(Phase Locked Loop), resulting in low cost. The control circuit is realized with analogue devices and the experimental results demonstrate the validity of the proposed control strategy.
\end{abstract}

Keywords-active filter; feed-forward control; analogue device; voltage control; electric current control

\section{INTRODUCTION}

With the development of power electronic technology and its wide application in industry, the pollution for power grid becomes more and more serious. Because the traditional passive filter has following shortcomings, such as unideal filtering effect, emerging syntony with power grid easily, it is gradually replaced by active power filter.

The fundamental principle of active power filter is to produce harmonic current (voltage) which is in the opposite direction of load harmonic current (voltage) but equal to its amplitude in order to eliminate harmful harmonic in power grid. It requires that the control of active power filter has better traceability and property for real-time. And a large number of literatures have done relative research works. On the search method of output current control reference signal acquisition, FFT detection method can detect the amplitude and phase of each harmonic, but it takes much calculation and time-delay; neural network detection method requires a lot of time to train samples, but it can not fulfill the real-time require. Although the adaptive ability of harmonic test which bases on adaptive cancellation of the principle is pretty well, and it has good track detection and high precision, but the weakness is slower dynamic response. Detection algorithm which bases on instantaneous reactive power theory can be respectively used to detect harmonic and reactive power but the algorithm is relatively complex; although the experience mode decomposition method reduces the complexity of detection algorithm in a certain extent, the calculation is still relatively large. On the search method of current tracking control, although adopting hysteresis loop control can obtain good dynamic tracking function, there are shortcomings of low control precision and switching frequency variation; the literature [11-12] makes the improvement on the hysteresis loop control and raises the control function, but it increases the complexity of control algorithm; although the sliding mode variable structure control has a good rapidity, it still exists the shortcomings of the steady-state error which cannot be eliminated; although the deadbeat control can quickly predict the change trend of harmonic current and it is easy to be implemented by computers, it has much dependence on the prediction model. Because of the complex algorithm, the prediction period will be increased, and it causes larger prediction error, ultimately affecting the compensation effect; Literature ${ }^{[15-16]}$ proposes an ideal on the generalized integrator to each integral to harmonics, so as to eliminate the steady-state error, but it will increase the amount of calculation and reducing the real-time control. Overall, these algorithms are much complex, and take high application cost.

In order to decrease impact current generated in grid voltage system start-up, this paper proposes a feed-forward control strategy of active power filter. This kind of control strategy is based on the method of current loop as the inter loop and of voltage loop as the outer loop, respectively measuring on control between grid current and inverter's DC side voltage. This strategy uses switch averaging model design controller and introduces the voltage feed-forward compensation to eliminate the effect on grid voltage and DC voltage to output current.

\section{SYSTEMS DESCRIPTION}

Figure. 1 is a structure diagram of single-phase active power filter. Respectively, $i_{L}(t) 、 i_{S}(t)$ and $i_{F}(t)$ are load current、grid current and filter current; $U_{S}(t)$ and $U_{C}(t)$ are grid voltage and DC voltage. L represents filtering inductance. Using switch averaging method can establish the model of dynamic mathematical model systems for:

$$
\begin{gathered}
L \dot{i}_{F}(t)=[2 d(t)-1] u_{C}(t)+u_{S}(t) \\
C \dot{u}_{C}(t)=[1-2 d(t)] i_{F}(t)
\end{gathered}
$$

Here, $d(t)$ is duty cycle. 


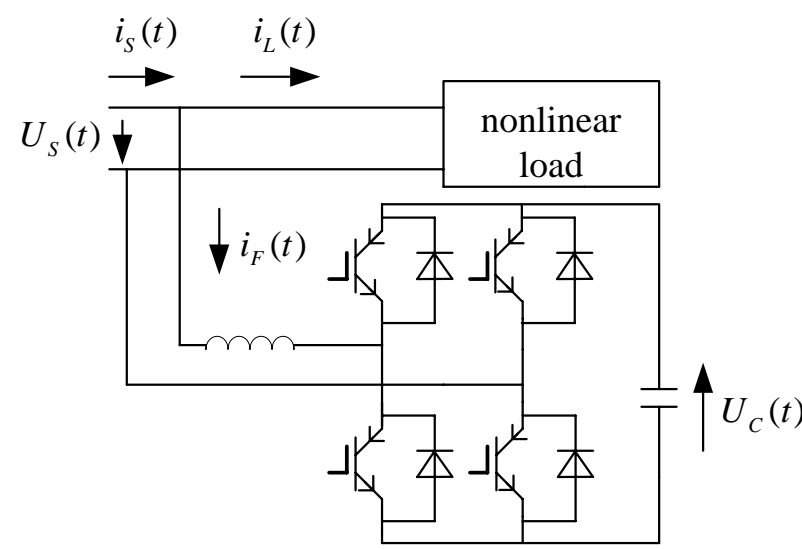

Figure.1 Schematic diagram of single-phrase active power filter

\section{CURRENT LOOP CONTROL}

\section{A. Current Loop Description}

Formula (1) shows, if the DC voltage $u_{C}(t)$ can be well controlled as $U_{C}$, the filter current can be approximated as:

$$
L \dot{i}_{F}(t)=2 U_{C} d(t)-u_{C}(t)+u_{S}(t)
$$

We can draw the current control block diagram showed in Figure.2. In the Figure, $i_{S}{ }^{*}(t)$ is grid current control reference signal and $G_{c c}(s)$ is the current controller.

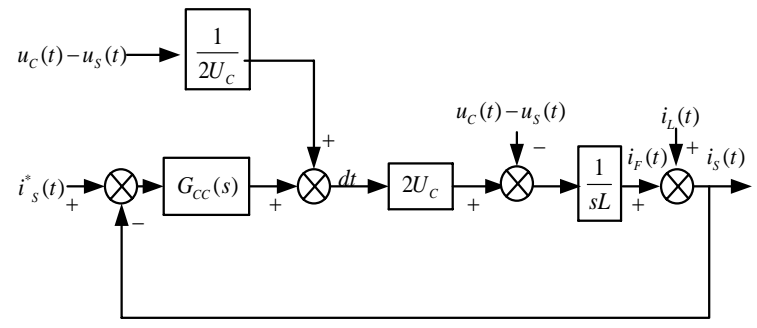

Figure.2 Current control loop

In order to eliminate the effect of grid voltage and DC voltage, this paper introduces a feed-forward controller, whose transfer function is:

$$
G_{F}(s)=\frac{1}{2 U_{C}}
$$

Current controller adopts the traditional PI algorithm:

$$
G_{C C}(s)=\frac{K_{P 0} s+K_{I 0}}{s}
$$

This paper, by using grid voltage producing sine factor of the grid current active components, makes sine factor multiplied by the output of voltage controller to get desired grid active current $i_{S}{ }^{*}(t)$. Thus, $i_{S}{ }^{*}(t)$ is the same frequency and phase sinusoidal quantity with grid voltage, the period of 20ms. So, the design of current controller parameters is particularly important.

\section{B. Design of Current Controller Parameters}

Figure. 2 shows, the transfer function of grid current for its control reference signal is:

$$
G_{0}(s)=\frac{I_{S}(s)}{I_{S}^{*}(s)}=\frac{2 U_{C}\left(K_{P 0} s+K_{I 0}\right)}{L s^{2}+2 U_{C}\left(K_{P 0} s+K_{I 0}\right)}
$$

Because $i_{S}^{*}(t)$ is a periodic quantity of 20ms, the closed loop transfer function requires a certain bandwidth to make the current loop has a good band pass characteristic for reference signal on $50 \mathrm{~Hz}$.

By Formula (5), the characteristic equation for current loop is:

$$
\Delta(s)=L s^{2}+2 U_{C}\left(K_{P 0} s+K_{I 0}\right)
$$

Undamped natural frequency $\omega_{I}$ of current loop is m times power frequency $f_{u}$, to:

$$
\omega_{I}=m 2 \pi f_{u}=\sqrt{\frac{2 U_{C} K_{I 0}}{L}} \quad m \geq 3
$$

Thus obtained:

$$
K_{I 0}=\frac{L\left(m 2 \pi f_{u}\right)^{2}}{2 U_{C}}
$$

Current loop's damping ratio $\xi_{I}$ by (9) to determine:

$$
2 \xi_{1} \omega_{I}=\frac{2 U_{C} K_{I 0}}{l}
$$

Critical damping design of current loop, namely $\xi_{I}=1$, available:

$$
K_{P 0}=\frac{L m 2 \pi f_{u}}{U_{C}}
$$

\section{VOLTAGE LOOP CONTROL}

\section{A. Voltage Loop Description}

This paper based on the energy balance theory, measures the inverter DC voltage. The control box as shown in Figure.3, $\alpha$ is the constant coefficient, $G_{c u}(s)$ for voltage controller. The working principle of voltage loop is that the DC capacitor voltage $U_{C}(t)$ is lower than the set point $U_{C}{ }^{*}(t)$, when the active power filter is started. $i_{S}{ }^{*}(t)$ is relatively higher, so it can control $i_{S}(t)$ containing the extra active current component to charge DC side capacitor, leading to $U_{C}(t)$ voltage rising. When the DC voltage reaches its 
expected stable voltage, the expected gird active current $i_{S}{ }^{*}(t)$ only contains the active component of load current $i_{L}(t)$ and the power consumption in electric current of inverter. Otherwise, DC voltage will change.

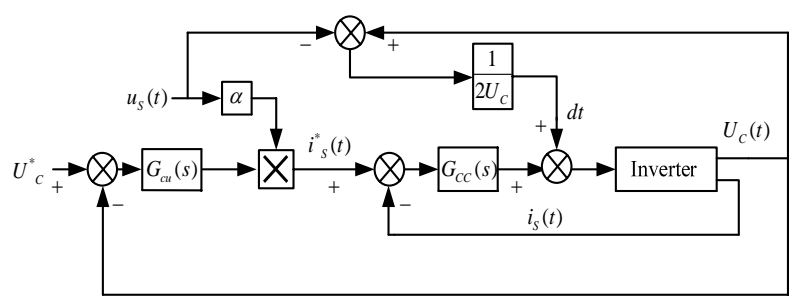

Figure.3 DC voltage control loop of inverter

In this paper, using traditional PI controller as the voltage loop controller tracks and controls the DC voltage:

$$
G_{c u}(s)=K_{P 1}+\frac{K_{I 1}}{s}
$$

\section{B. Parameters Design of the Voltage Controller}

According to the principle of energy conservation, available:

$$
P_{S}(t)=P_{L}(t)+P_{F}(t)
$$

Among them, $P_{S}(t), P_{L}(t)$ and $P_{F}(t)$, they respectively mean the active power of grid output, the active power of load absorption and the active power of grid connected inverter system absorption.

If the current loop can well control $i_{S}(t)$ and track $i_{S}^{*}(t)$, it means:

$$
i_{S}(t)=i_{S}^{*}(t)=\alpha u_{S}(t) w(t)
$$

Among them, $w(t)$ as the voltage controller output, then it gets:

$$
P_{S}(t)=U_{S} I_{S}(t)=\alpha w(t) U_{s}^{2}
$$

Among them, $U_{S}$ and $i_{S}(t)$ are effective values of voltage and current.

Ignoring the loss of inverter, the voltage changes of DC capacitor $\mathrm{C}$ is determined by active power $P_{F}(t)$ of inverter's absorption:

$$
\int_{0}^{t} P_{F}(t) d t=\frac{1}{2} C\left[U_{C}+\Delta u c(t)\right]^{2}-\frac{1}{2} C U_{C}^{2}
$$

On (15), for Laplace transform and ignoring the effect of $\Delta u_{C}^{2}(t)$ available:

$$
\Delta u_{C}(s)=\frac{P_{F}(s)}{s C U_{C}}
$$

So we can draw the DC voltage $u_{C}(t)$ incremental control block diagram that is shown in Figure.4. In figure, $G_{u}(s)=1 /\left(s C U_{C}\right)$.

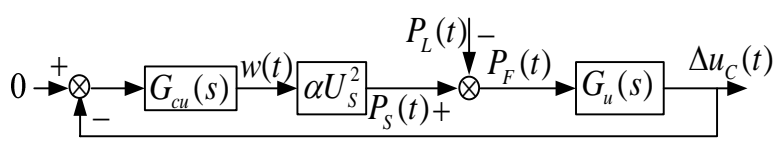

Figure.4 Block diagram of DC voltage increment control

As shown in Figure.4, we can get the characteristic equation for the voltage loop:

$$
\Delta(s)=C U_{C} s^{2}+\alpha U_{S}^{2} K_{P 1} s+\alpha U_{S}^{2} K_{I 1}
$$

In order to reduce the influence of the DC voltage by grid voltage and load current, natural frequency of voltage loop for power frequency $f_{u} 1 / \mathrm{n}$, gets:

$$
\omega_{u}=\frac{2 \pi f_{u}}{n}=\sqrt{\frac{\alpha U_{S}^{2} K_{I 1}}{C U_{C}}}
$$

Thus obtained:

$$
K_{I 1}=\frac{\left(2 \pi f_{u}\right)^{2} C U_{C}}{n^{2} \alpha U_{S}^{2}}
$$

Voltage loop’s damping ratio meets:

$$
2 \xi_{u} \omega_{u}=\frac{\alpha U_{S}^{2} K_{P 1}}{C U_{C}}
$$

The voltage loop critical damping, $\xi_{I}=1$, to:

$$
K_{P 1}=\frac{2 \pi f_{u} C U_{C}}{n^{2} \alpha U_{S}^{2}}
$$

\section{EXPERIMENTAL INSTALLATION}

To verify the proposed method, an experimental prototype is manufactured in this paper. Inverter uses IPM module construction of Mitsubishi Company and the module type is PM15CSJ060. Filter inductance is $500 \mu \mathrm{H}$, and DC capacitor is $470 \mu \mathrm{F}$; inverter DC side voltage is $400 \mathrm{~V}$, and switching frequency is $20 \mathrm{kHz}$; If we use parameter $\alpha=0.01$, which makes the maximum value of $\alpha u_{s}(t)$ about $3.11 \mathrm{~V}$ (power supply voltage is $220 \mathrm{~V}$ ), we ensure that the multiplier output will not saturate easily; if we use parameter $m=3$, we can get the current loop controller parameters $K_{P 0}$ and $K_{I 0}$ respectively are 0.0012 and 0,56 ; if we use parameter $n=10$, we can get the voltage loop controller parameters 
$K_{P 1}$ and $K_{I 1}$ respectively are 0.017 and 0.27 ; The power supply voltage is $220 \mathrm{~V}$, frequency for $50 \mathrm{~Hz}$; harmonic source for the two diode bridge rectifier with resistance capacitance load

\section{EXPERIMENTAL RESULT}

Figure. 5 shows waveform and spectrum before the filter process, we can see the grid current serious distortion without active power filter.
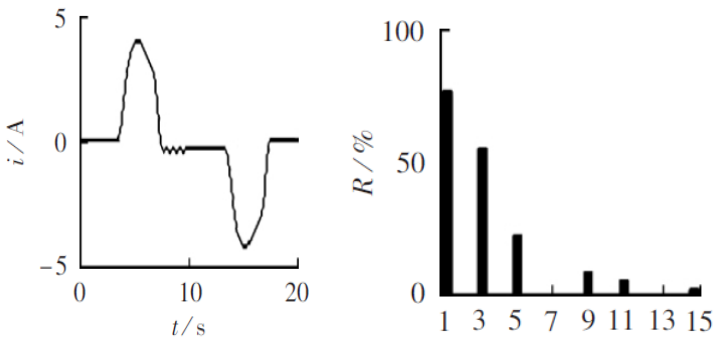

Figure.5 Waveform and spectrum of grid current without active power filter

Figure.6 shows the steady waveform and spectrum of grid current after active power filter worked, which used the method from this paper. We can see that every harmonics of grid current equally gets effective filtering. Before getting filtering, the total distortion rate of grid current is $61.8 \%$, and after getting filtering it is $6.6 \%$; the power factors are respectively 0.77 and 0.99 .
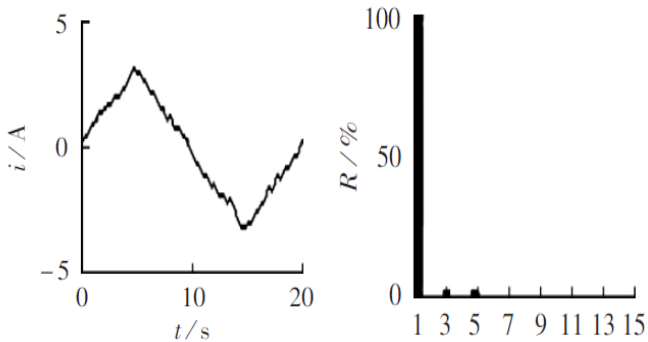

Figure.6 Waveform and spectrum of grid current with proposed active power filter

Figure.7 shows the dynamic response waveform which has not introduced the active power filter of feed-forward control. We can see that large impulse current is produced by active power filter.

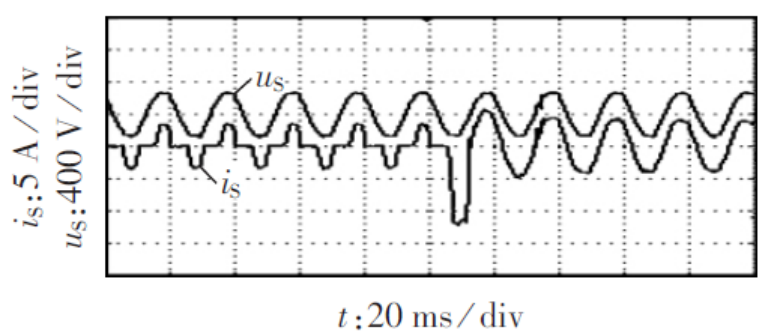

Figure.7 Dynamic response waveform of active power filter without feed-forward controller

Figure.8 shows the dynamic response waveform which has introduced the active power filter of feed-forward control. We can see that small impulse current produced by active power filter.

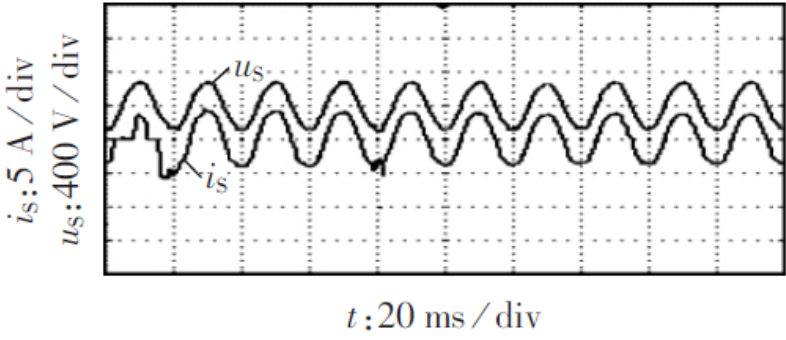

Figure.8 Dynamic response waveform of active power filter with feed-forward controller

\section{CONCLUSION}

This paper manufactures a low cost active power filter and realizes harmonic and reactive power compensation at the same time. The switch averaging method makes modeling and analysis to high switching frequency of inverter, introducing the feed-forward control to reduce the grid voltage and DC voltage on the effect of controlled current and restraining impact current when the grid voltage system starts up. What's more, it uses the control of DC voltage, without complex mathematical operation, to directly obtain the reference signal of controlled current, simplifying the control algorithm and simultaneously saving detection circuit and PLL circuit of load current.

\section{REFERENCES}

[1] SINGH B, AL-HAD DAD K, CHANDRA A. A review of active power filters for power quality improvement [J]. IEEE Trans Ind Electron, 1999, p. 960-971.

[2] GRADY W M, SAMOTYJ M J, NOYOLA A H. Survey of active line conditioning methodologies[J]. IEEE Trans on Power Delivery, 1990, p. 1536-1542.

[3] QU Yilong, TAN Weipu, MA Yao, et al. An adaptive harmonic detection method using fuzzy LMS algorithm [J]. Automation of Electric Power Systems, 2008, p. 42-46.

[4] LI Qiao, WU Jie. Simulation study of adaptive harmonic current detection method for active power filters [J]. Transactions of China Electrotechnical Society, 2004, p. 86-90.

[5] ZHAO Wei, LUO An, CAO Yijia, et al. Hybrid var and harmonic dynamic compensator and application to three-two phase traction substation [J].. Proceedings of the CSEE, 2009, 29(28): 107-113.

[6] ZHOU Ke, LUO An, XIA Xiangyang. An improved ip-ic harmonic current detecting method and digital low-pass filter's optimized design [J]. Proceedings of the CSEE, 2007, p. 96-101.

[7] FU Qing, YANG Geng, GUO Xizheng. Control method for active power filter considering harmonic voltage in power source [J]. Transactions of China Electrotechnical Society, 2006, p. 47-51.

[8] WU Jingbing, LUO An. Iterative learning control for current tracking of hybrid active power filter [J]. Electric Power Automation Equipment, 2011, p. 58-61.

[9] YANG Xiaoping, LIU Pusen, ZHONG Yanru. Harmonic detection of active power filter based on empirical mode decomposition [J]. Transactions of China Electrotechnical Society, 2009, p. 197-201.

[10] MALESANI L, MATTAVELLI P, TOMASIN P. High-performance hysteresis modulation technique for active filters [J]. IEEE Transactions on Power Electronics, 1997, p. 876-884.

[11] ZENG Jiang, LIU Yan, YE Xiaojun, etal. A novel hysteresiscurrent control method for active power filter with low switching loss [J]. Power System Technology, 2010, p. 73-78.

[12] ANG Xin, HU Xinxin. APF without the DC voltage sensor [J]. Electric Power Automation Equipment, 2011, p. 31-33.

[13] DENG Zhanfeng, ZHU Dongqi, JIANG Xinjian. A hybrid power filter based on sliding mode control [J]. Transactions of China 
Electrotechnical Society, 2002, p. 92-95.

[14] FENG Yu, SHI Liping, LIU Changjiang. Beat control algorithmof active power filter with objective function optimized [J]. Power System Technology, 2006, p. 77-80.

[15] YUAN Xiaoming, MERK W, STEMMLER H. Stationary-frame generalized integrators for current control of active power filters with zero steady-state error for current harmonics of concern under unbalanced and distorted operating conditions [J]. IEEE Transactions on Industry Applications, 2002, p. 523-532.

[16] SMEDLEY K M, ZHOU Luowei, QIAO Chongming. Unified constant frequency integration control of active power filters steady-state and dynamics [J]. IEEE Trans on Power Electronics,2001, p. 428-436. 